\title{
Optimized steps in determination of malondialdehyde (MDA) standards to diagnostic of lipid peroxidation
}

\author{
Prima Nanda Fauziah*, "Ani Melani Maskoen**, Tri Yuliati***, Erlina Widiarsih**** \\ *Medical Laboratory Technology Study Programme General Achmad Yani School of Health Science, \\ Indonesia \\ **Department of Oral Biology Faculty of Dentistry Universitas Padjadjaran, Indonesia \\ *** Integrated Research and Testing Laboratory Gadjah Mada University, Indonesia \\ ${ }^{* * * *}$ Laboratory of Molecular Genetic Faculty of Medicine Universitas Padjadjaran, Indonesia
}

\begin{abstract}
Introduction: Lipid peroxidation, one of known indices of oxidative stress, is documented in various diseases. secondary oxidation products such as malondialdehyde (MDA) is commonly measured to observe lipid peroxidation. In this study, a spectrophotometric method was evaluated to measure thiobarbituric acid reactive substances (TBARS) with high sensitivity. MDA is a known biomarker of oxidative status in a biological system. This study aimed to optimization standard of MDA using tetraethoxypropane (TEP) 97\% ( $F W=220.3$ ). Methods: The method is based upon reaction of malondialdehyde (MDA) and TBA in the glacial acetic acid medium. This research consists of two phases: first, making stock of TEP; and the second phase was testing the concentration of TEP for finding the standard curve of MDA before used in diagnostic of lipid peroxidation. Results: Result showed the concentration 1,875-60 uM of TEP can form a precise standard curve. Conclusion: In the concentration 1,875-60 uM of TEP can be used as a reference as standard of control in diagnostic of lipid peroxidation using TBARS method.
\end{abstract}

Keywords: Concentration, standard curve, TBARS, tetraethoxypropane.

p-ISSN: 1979-0201; e-ISSN: 2549-6212; Available from: http://jurnal.unpad.ac.id/pid/article/view/18329

DOI: http://dx.doi.org/10.24198/pid.vol30no2.18329

Submission: November 27, 2017; Accepted: July 6, 2018; Published online: July 31, 2018

INTRODUCTION

Oxidative stress occurs due to imbalance of oxidants and defense systems of an organism. ${ }^{1}$ Oxidants comprise of reactive oxygen species (ROS), reactive nitrogen species (RNS), sulfurcentered radicals and others. The reactive nonradical species are often found as radicals, which enhance the reaction, resulting in damage.
Oxidants can be produced through ionizing radiation, chemical reactions, and redoxcatalysis mediated by free transition metal ions, or metal ions bound to enzymes. Important cellular sources of oxidative stress are: (a) the formation of ROS by incomplete reduction of oxygen in mitochondrial respiration, and (b) host defense systems, which include the $\gg$ oxidative burst « facilitated by NADPH oxidase, generating

\#Corresponding author: Ani Melani Maskoen, Department of Oral Biology Faculty of Dentistry Universitas Padjadjaran, Indonesia

Sekeloa Selatan I, Bandung 40132, Indonesia. E-mail: amelani@yahoo.com 
superoxide radical, and myeloperoxidase, leading to the formation of hypochlorous acid. ${ }^{2}$ Lipid peroxidation is one of known indices of oxidative stress and contributing factor in degenerative diseases, ${ }^{3}$ cardiovascular disease, Parkinson's disease, Alzheimer's disease, ${ }^{4}$ and psychiatric disorders, including schizophrenia. ${ }^{5}$ Assesment of primary lipid peroxidation products (hydroperoxides) is usually unstable due to its reactive nature. ${ }^{6}$ Therefore, measurement of secondary oxidation products such as malondialdehyde (MDA) is commonly conducted to observe lipid peroxidation.

This distinctive compound has long been a model compound to observe secondary degradation products of lipid peroxidation. The condensation of MDA with two molecules of 2-thiobarbituric acid (TBA) has been the common marker to observe oxidative damage of lipids. ${ }^{7-9}$ The absorbance of the complex is usually determined using spectrophotometry or spectrofluorometry, ${ }^{10}$ or by specific techniques, also based on TBA-mixture, where HPLC separation with spectrophotometric or spectrofluorometric or MS detection is enrolled. Hence, a spectrophotometric method was evaluated in the present study to measure thiobarbituric acid reactive substances (TBARS). This study aimed to optimization standard of MDA using tetraethoxypropane (TEP) 97\% (FW=220.3).

\section{METHODS}

This research consists of two phases: first, making stock of TEP. The second phase was testing the concentration of TEP for finding the standard curve of MDA before used in diagnostic of lipid peroxidation. Level of MDA was measured with TBARS (thiobarbituric acid-reactive substances) from NWLSSTM Malondialdehyde Assay Northwest (NWK-MDA01). Cells were treated with liquid containing $15 \% \mathrm{w} / \mathrm{v}$ trichloroacetic acid, 0,375 $\mathrm{w} / \mathrm{v}$ thiobarbituric acid, 0,25 hydrichloric acid and $0,2 \%$ triton $X$. Furthermore, cells were carried and suspended with heating at $100^{\circ} \mathrm{C}$ for 15 minutes, and centrifuged at $4500 \mathrm{rpm}$ for $10 \mathrm{~min}$. Supernatant was measured with spectrophometer at $532 \mathrm{~nm}$ wavelength. ${ }^{11}$

\section{RESULTS}

Table 1. The concentration 1,875 until 60 uM of TEP can form a precise standard curve

\begin{tabular}{cccccccc}
\hline \multirow{2}{*}{ No } & \multicolumn{7}{c}{ Standard concentration $(\mu \mathrm{M})$} \\
\cline { 2 - 8 } & 60 & 30 & 15 & 7.5 & 3.75 & 1.875 & 0 \\
\hline 1 & 1.584 & 0.812 & 0.400 & 0.188 & 0.096 & 0.048 & 0.001 \\
2 & 0.639 & 0.289 & 0.168 & 0.090 & 0.052 & 0.036 & 0.003 \\
3 & 0.674 & 0.337 & 0.170 & 0.085 & 0.045 & 0.020 & 0.005 \\
4 & 0.678 & 0.249 & 0.130 & 0.070 & 0.029 & 0.013 & 0.007 \\
5 & 0.87 & 0.458 & 0.203 & 0.101 & 0.037 & 0.017 & 0.007 \\
6 & 1.486 & 0.730 & 0.395 & 0.195 & 0.098 & 0.054 & 0.009 \\
7 & 1.584 & 0.812 & 0.4 & 0.188 & 0.096 & 0.048 & 0.001 \\
8 & 0.759 & 0.421 & 0.223 & 0.089 & 0.064 & 0.024 & 0.004 \\
9 & 0.982 & 0.455 & 0.177 & 0.11 & 0.057 & 0.03 & 0.007 \\
10 & 0.984 & 0.589 & 0.186 & 0.092 & 0.054 & 0.029 & 0.009 \\
11 & 1.526 & 0.804 & 0.388 & 0.142 & 0.059 & 0.025 & 0.01 \\
12 & 1.541 & 0.814 & 0.419 & 0.215 & 0.102 & 0.063 & 0.008 \\
13 & 0.973 & 0.452 & 0.178 & 0.112 & 0.061 & 0.032 & 0.006 \\
14 & 0.712 & 0.335 & 0.173 & 0.086 & 0.05 & 0.021 & 0.006 \\
15 & 0.762 & 0.424 & 0.226 & 0.092 & 0.067 & 0.027 & 0.007 \\
16 & 0.98 & 0.453 & 0.175 & 0.108 & 0.055 & 0.028 & 0.007 \\
\hline
\end{tabular}

\section{DISCUSSION}

Reactive oxygen species and particularly free radical induced lipid peroxidative tissue damage have been involved in many diseases. Lipid peroxidation is indirectly measured through its secondary products, such as malondialdehyde (MDA). ${ }^{12}$ MDA is a three-carbon low molecular weight aldehyde and spontaneous breakdown product of peroxides derived from free radical attack on poly unsaturated fatty acids. ${ }^{13-16}$

The common method for the assessment of MDA level is thiobarbituric acid (TBA) assay, which is a spectrophotometric assay based upon heating of the sample under acidic conditions to form the adduct of MDA-TBA. ${ }^{14,17-18}$ MDA is formed through the hydrolysis of tetraethoxypropane (TEP). In this study, result showed the TEP in range of 1,875-60 uM can form a precise standard curve. TBA can react with other carbonyl-containing compounds and results in high MDA levels. ${ }^{19}$ MDA levels can be seen from the color changed be pink solution and calculated using a linear standard curve with micro molar $(\mathrm{mM})$ units. 
The rapidity, ease of use and cost of TBA assay made it the most common method. The reaction rate depends on temperature, $\mathrm{pH}$ and concentration of TBA. The reaction is carried out in acidic solution and temperature of $\sim 100^{\circ} \mathrm{C}$ within one hour and most of MDA is produced during reaction process from decomposition of products of lipid peroxidation. ${ }^{20}$

Nevertheless, it has been reported that there are some limitations of this method. ${ }^{20}$ TBA reactivity is non-specific on MDA in which crossreaction of other aldehydes produced from lipid peroxidation. Thus, total values of TBA reactive substances (TBARs) is usually measured as a biomarker of oxidative stress instead of MDA values. Other disadvantages include effects of procedural modifications on MDA-TBA adduct development, low stability of MDA in biological samples due to its high tendency for reacting with protein and rapid enzymatic degradation, poor reproducibility of analytical results and low recovery test results.

\section{CONCLUSION}

TEP in range of $1.875-60$ uM can form a precise standard curve which will be further used as standard of control in diagnostic of lipid peroxidation using TBARS method.

\section{REFERENCES}

1. Berridge M V, Tan A S, McCoy K D, Wang R 1996 The biochemical and cellular basis of cell proliferation assay that use tetrazolium salts. Biochemica 4: 15-20.

2. Halliwell B, Gutteridge J M C 2000 Free Radicals in Biology and Medicine. Third edition. Oxford Science Publications, New York, Oxford University Press.

3. Pasupathi P., Chandraseker V., Kumar U. S. 2009. Evaluation of oxidative stress, antioxidant and thyroid hormone status in patients with diabetes mellitus. J. Med. 10: 60-66

4. Adly A. A. M. 2010. Oxidative stress and disease: an updated review. Res. J. Immunol. 3: $129-145$

5. Tsaluchidu S., Cocchi M., Tonnello L., Puri B. K. 2008. Fatty acids and oxidative stress in psychiatric disorders. BMC Psychiatry. 8 (Suppl): $1-3$

6. Zeb A, Ullah F. A simple spectrophotometric method for the determination of thiobarbituric acid reactive substances in fried fast foods. J. Anal. Methods. Chem. 2016;2016.

7. Gray J I 1978 Measurement of lipid oxidation: A review. J Am Oil Chem Soc 55: 539-46

8. Ayala A, Muñoz MF, Argüelles S. Lipid peroxidation: production, metabolism, and signaling mechanisms of malondialdehyde and 4-hydroxy-2-nonenal. Oxid. Med. Cell. Longev. 2014;2014.

9. Barriuso B, Astiasarán I, Ansorena D. A review of analytical methods measuring lipid oxidation status in foods: a challenging task. Eur. Food. Res. Technol. 2013;236(1):1-5.

10. Matumoto-Pintro PT, Murakami AE, Vital ACP, Croge C, da Silva DF, Ospina-Roja, IC. Guerra AFQG. Effects of storage time and temperature on lipid oxidation of egg powders enriched with natural antioxidants. Food. Chem. 2017;228:463-468.

11. Gunardi J.I., Mose j., Mieke H.S., Anita D.A., Prima N.F., Triyuli. Effects of Papua Ant Nests (Myrmecodia pendens) on Level of sFlt-1, PIGF, MDA and NO in Preeclampsia-induced HUVEC Cell Line. Int. J. PharmTech. Res. 2016, 9(6), 424-435

12. Anoopkumar-Dukie S, Walker RB, Daya S. A sensitive and reliable method for the detection of lipid peroxidation in biological tissues. J Pharm Pharmacol 2001; 53: 263-6

13. Cordis GA, Das DK, Riedel W. High-performance liquid chromatographic peak identification of 2, 4- dinitrophenylhydrazine derivatives of lipid peroxidation aldehydes by photodiode array detection. J Chromatogr A 1998; 798: 117-23

14. Templar J, Kon SP, Milligan TP, Newman DJ, Raftery MJ. Increased plasma malondialdehyde levels in glomerular disease as determined by a fully validated HPLC method. Neprol Dial Transplant 1999; 14: 946-51

15. Slatter DA, Bolton CH, Bailey AJ. The importance of lipidderived malondialdehyde in diabetes mellitus. Diabetologia 2000; 43: 550-7

16. Pilz J, Meineke I, Gleiter $\mathrm{CH}$. Measurement of free and bound malondialdehyde in plasma by 
high-performance liquid chromatography as the 2,4-dinitrophenylhydrazine derivative. J Chromatogr B Biomed Sci Appl 2000; 742: 31525

17. Dib M, Garrel C, Favier A, Robin V, Desnuelle C. Can malondialdehyde be used as a biological marker of progression in neurodegenerative disease? J Neurol 2002; 249: 367-74

18. Ceconi C, Cargnoni A, Pasini E, Condorelli E, Curello S, Ferrari R. Evaluation of phospholipid peroxidation as malondialdehyde during myocardial ischemia and reperfusion injury. Am J Physiol 1991; 260: H1057-61

19. Tukozkan N, Erdamar H, Ilgim S. Measurement of Total Malondialdehyde in Plasma and Tissues by High-Performance Liquid Chromatography and Thiobarbituric Acid Assay. Firat Tip Dergisi 2006;11(2): 88-92

20. Khoubnasabjafari M, Ansarin K., Jouyban A. Reliability of malondialdehyde as a biomarker of oxidative stress in psychological disorders. Biolmpacts: BI 2015;5(3): 123 